\title{
From integrative disease modeling to predictive, preventive, personalized and participatory (P4) medicine
}

\author{
Erfan Younesi ${ }^{1,2^{*}}$, Martin Hofmann-Apitius ${ }^{1,2+}$ \\ From EPMA-World Congress 2013 \\ Brussels, Belgium. 20-21 September 2013
}

With the significant advancement of highthroughput technologies and diagnostic techniques throughout the past decades, molecular underpinnings of many disorders have been identified. However, translation of patient-specific molecular mechanisms into tailored clinical applications remains a challenging task, which requires integration of multi-dimensional molecular and clinical data into patient-centric models. This task becomes even more challenging when dealing with complex diseases such as neurodegenerative disorders. Integrative disease modeling is an emerging knowledgebased paradigm in translational research that exploits the power of computational methods to collect, store, integrate, model and interpret accumulated disease information across different biological scales from molecules to phenotypes. We argue that integrative disease modeling will be an indispensable part of any P4 medicine research and development in the near future and that it supports the shift from descriptive to causal mechanistic diagnosis and treatment of complex diseases. For each 'P' in P4 medicine, we demonstrate how integrative disease modeling can contribute to addressing the real-world issues in development of new predictive, preventive, personalized and participatory measures. With the increasing recognition that application of integrative systems modeling is key to all activities in $\mathrm{P} 4$ medicine, we envision that translational bioinformatics in general and integrative modeling in particular will continue to open up new avenues of scientific research

\footnotetext{
* Correspondence: erfan.younesi@scai.fraunhofer.de

† Contributed equally

'Department of Bioinformatics, Fraunhofer Institute for Algorithms and Scientific Computing (SCAl), Schloss Birlinghoven, 53754 Sankt Augustin, Germany

Full list of author information is available at the end of the article
}

for current challenges in P4 medicine as outlined in the concluding part of this paper.

\section{Authors' details}

'Department of Bioinformatics, Fraunhofer Institute for Algorithms and Scientific Computing (SCAl), Schloss Birlinghoven, 53754 Sankt Augustin, Germany. ${ }^{2}$ Rheinische Friedrich-Wilhelms-Universität Bonn, Bonn-Aachen International Center for IT, Dahlmannstr. 2, 53113 Bonn, Germany.

Published: 11 February 2014

\section{doi:10.1186/1878-5085-5-S1-A49}

Cite this article as: Younesi and Hofmann-Apitius: From integrative disease modeling to predictive, preventive, personalized and participatory (P4) medicine. EPMA Journal 2014 5(Suppl 1):A49.
Submit your next manuscript to BioMed Central and take full advantage of:

- Convenient online submission

- Thorough peer review

- No space constraints or color figure charges

- Immediate publication on acceptance

- Inclusion in PubMed, CAS, Scopus and Google Scholar

- Research which is freely available for redistribution
() Biomed Central 